\title{
Leucocyte-endothelial cell adhesion in a model of intestinal inflammation
}

\author{
H Arndt, K-D Palitzsch, D C Anderson, J Rusche, M B Grisham, D N Granger
}

\begin{abstract}
Leucocyte-endothelial cell adhesion is modulated by a variety of adhesion glycoproteins expressed on the surface of leucocytes and endothelial cells. Although in vitro studies show that these adhesion molecules mediate the decrease in leucocyte rolling velocity and the increase in leucocyte adherence and emigration associated with inflammation, there are few in vivo data to support this hypothesis. The aim of this study was to assess the role of leucocyte (CD11b/CD18) and endothelial cell ( $P$ - and E-selectin) adhesion molecules in mediating the leucocyte-endothelial cell adhesion elicited in rat mesenteric venules during a model of longlasting intestinal inflammation. Indomethacin was injected 48 and 24 hours before the experiment. The mesenteric microcirculation was observed by intravital microscopy in animals treated with monoclonal antibodies (MAb) directed against either P-selectin, Eselectin, or CD11b/CD18. Leucocyte rolling velocity, and the number of adherent and emigrated leucocytes as well as vessel diameter and erythrocyte velocity were monitored in roughly $30 \mu \mathrm{m}$ diameter postcapillary venules. Indomethacin treatment resulted in mucosal ulceration and granulocyte infiltration, and a corresponding inflammatory response in the mesentery, which was characterised by an increase in the number of adherent (eightfold) and emigrated (sixfold) leucocytes and a reduction $(80 \%)$ in leucocyte rolling velocity. The indomethacin induced leucocyte-endothelial cell adhesion in mesenteric venules was significantly reduced by treatment with MAbs against either CD11b/CD18 or E-selectin, but not by the P-selectin MAb. These results suggest that both leucocyte (CD11b/CD18) and endothelial cell (E-selectin) adhesion molecules contribute to the granulocyte accumulation in a chronic model of intestinal inflammation.

(Gut 1995; 37: 374-379)
\end{abstract}

Keywords: indomethacin, integrins, P-selectin, E-selectin, microcirculation, inflammatory bowel disease.

The accumulation of leucocytes in inflamed tissue is preceded by leucocyte adhesion to vascular endothelium. This rate limiting step in the inflammatory response is modulated by a variety of adhesion glycoproteins expressed on the surface of leucocytes and endothelial cells.
Recent in vitro studies show that different adhesion molecules participate in the low affinity binding that is manifested as leucocyte rolling and the high affinity binding associated with firm adhesion of leucocytes. P- and E-selectin are calcium dependent endothelial cell surface lectins that mediate leucocyte adhesion by recognition of cell specific carbohydrate ligands. P-selectin, which is stored in the Weibel-Palade bodies ${ }^{1}$ interacts with the oligosaccharide sialyl Lewis $x,{ }^{23}$ and is proposed to mediate leucocyte rolling. ${ }^{4}$ The expression of $P$-selectin at the cell surface resulting from exposure to histamine, hydrogen peroxide, and thrombin occurs quickly, but is short lived and declines within minutes. ${ }^{56}$ The cytokine inducible expression of E-selectin peaks in four to six hours, declines to basal values by $24-48$ hours, and requires de novo RNA and protein synthesis. ${ }^{7}$ The selectins bind to sialyl Lewis $\mathbf{x}$ and Lewis a oligosaccharides on the leucocyte surface $^{89}$ and seem to be required for leucocyte rolling and transendothelial migration. ${ }^{10}$ Leucocyte adherence seems to be mediated by the CD11b/CD18 adhesion glycoprotein complex on leucocytes, which interacts with its ligand, intercellular adhesion molecule-1 (ICAM-1), on endothelial cells. ${ }^{11}$ The binding of CD11b/ CD18 to ICAM-1 is essential for neutrophil emigration as shown in in vitro transmigration assays. ${ }^{1112}$

Recent in vivo studies show that monoclonal antibodies (MAbs) against leucocyte (CD11/CD18) and endothelial cell (E-selectin, ICAM-1) adhesion molecules attenuate the recruitment of rolling, adherent, and emigrating leucocytes elicited by acute exposure of the mesenteric microcirculation to either leuketriene $\mathbf{B}_{4}$, platelet activating factor or low venular shear rates, while an anti-Pselectin $\mathrm{MAb}$ attenuates the rolling responses elicited by either platelet activating factor or low shear rates. ${ }^{13} 14$ In addition, these MAbs significantly reduce the leucocyte adhesion and albumin leakage responses induced by acute exposure of the microcirculation to L-NAME, an inhibitor of nitric oxide synthesis. ${ }^{15}$

While the aforementioned studies have provided much insight regarding the contribution of different adhesion molecules to the leucocyte-endothelial cell interactions associated with different acute (within minutes) inflammatory reactions, it remains unclear whether these adhesion molecules are equally important in modulating the leucocyte sequestration seen in tissues inflamed for days or weeks. Thus, the main objective of this study was to determine the contribution of three adhesion glycoproteins, CD11b/CD18, P-selectin and E-selectin, to the recruitment of 
adherent leucocytes seen in a model of longlasting (days) intestinal inflammation. Subcutaneously administered indomethacin was used to induce an intense inflammatory response in the small intestine and mesentery that peaks 48 hours after induction and persists for a period of at least 14 days. ${ }^{16} 17$

\section{Methods}

\section{Animal preparation}

Male Sprague-Dawley rats (160-240 g) were housed in standard wire mesh bottom cages in a room with a constant temperature of $25^{\circ} \mathrm{C}$ and a 12:12 hour light-dark cycle. The rats were given water and standard laboratory rat chow ad libitum. After anaesthesia with $110 \mathrm{mg} / \mathrm{kg}$ Inactin (Na-5-ethyl-1(1'-methyl-propyl)2-thiobarbiturate, Byk Gülden, Konstanz, Germany) a tracheotomy was performed, and the left carotid artery was cannulated for continuous measurement and recording of systemic blood pressure and heart rate (Statham P23A Transducer, Oxnard, CA; Grass Recorder, Grass Instruments, Quincy, MA).

\section{Intravital microscopy}

Animals were placed in a supine position on an adjustable Plexiglas microscope stage and the exteriorised segment of the mid-jejunum was draped over an optically clear viewing pedestal permitting transillumination of a $2 \mathrm{~cm}^{2}$ section, as described previously. ${ }^{18} 19$ The exposed bowel wall was draped with saline soaked gauze, the mesentery was covered with Saran Wrap (Dow Chemical, Indiana), and continuously superfused with warm bicarbonate buffered salt solution (BBS, pH 7.4) bubbled with $5 \% \mathrm{CO}_{2-}$ $95 \% \mathrm{~N}_{2}$. The temperature of the pedestal was maintained at $37^{\circ} \mathrm{C}$ by a constant temperature circulator (Fisher Scientific, model 80).

Single unbranched mesenteric venules of 25-35 $\mu \mathrm{m}$ diameter and roughly $150 \mu \mathrm{m}$ length were transilluminated with a $12 \mathrm{~V}-100 \mathrm{~W}$ light source and observed through an intravital video microscope (Leitz Ortholux II, Germany) with a $\times 40$ objective lens (Zeiss UD $40 / 0 \cdot 65$, Germany) and a $\times 10$ eyepiece. A video camera (Hitachi WK-C150, Japan) mounted on the microscope projected the image onto a colour monitor (Sony PVM2030, Japan). The images were recorded using a video cassette recorder (Panasonic NV8950, Japan) for playback analysis. Venular diameter $\left(D_{v}\right)$ was measured on or off line using a video image shearing monitor (IPM, LaMesa, CA). Red blood cell centreline velocity was measured on line with an optical Doppler velocimeter (Microcirculation Research Institute, Texas A\&M University). Mean red blood cell velocity was calculated assuming $\mathrm{V}_{\text {mean }}=$ centreline velocity $/ 1 \cdot 6 .^{20}$ Venular shear rate $(\gamma)$ was calculated based on the Newtonian definition ${ }^{21}: \gamma=8\left(\mathrm{~V}_{\text {mean }} / \mathrm{D}_{\mathrm{v}}\right)$.

The number of adherent and emigrated leucocytes were determined during playback of videotaped images. A leucocyte was defined as adherent to venular endothelium if it was stationary for at least 30 seconds. Leucocyte adherence was expressed as the number/ $100 \mu \mathrm{m}$ length of the venule. Leucocyte emigration was expressed as the number of white blood cells per microscopic field $\left(1.7 \times 10^{-2} \mathrm{~mm}^{2}\right)$. Rolling leucocytes were defined as white blood cells moving at a slower velocity than erythrocytes in the same vessel. The leucocyte rolling velocity $\left(V_{w b c}\right)$ was determined from the time a leucocyte required to move along $100 \mu \mathrm{m}$ of the microvessel. A mean of 10 estimates of transit time was used to calculate $\mathrm{V}_{\text {wbc }}{ }^{18}$

\section{Experimental protocol}

Thirty rats were divided into five groups. Four groups received two subcutaneous injections of indomethacin 48 and 24 hours before the experiment $(10 \mathrm{mg} / \mathrm{ml} 5 \%$ $\mathrm{NaHCO}_{3}, 7.5 \mathrm{mg} / \mathrm{kg}$ each). ${ }^{17}$ Three groups were treated additionally with different MAbs given intravenously under ether anaesthesia at 24 hours and 12 hours before the experiment. The MAbs used in this study were IB6 (anti$\mathrm{CD} 11 \mathrm{~b}, 1.0 \mathrm{mg} / \mathrm{kg}$ intravenously), CL3 (antiE-selectin, $2.0 \mathrm{mg} / \mathrm{kg}$ ), and PB 1.3 (anti-P-selectin, $2.0 \mathrm{mg} / \mathrm{kg}$ ). IB6 (group 2) was provided by Repligen Corporation (Cambridge, MA), CL3 (group 3) by UpJohn Laboratories (Kalamazoo, MI), and PB 1.3 (group 4) by Cytel Corporation (San Diego, CA). The concentration of IB6 used in our experiments blocks rat neutrophil adherence to endothelial cells in vitro, ${ }^{22}$ CL3 reduced neutrophil accumulation in a glycogen induced peritonitis, and PB 1.3 inhibits adhesion of rat platelets to neutrophils. ${ }^{23}$ None of the antibodies or its solvent (saline) show an intrinsic effect on the microcirculatory parameters. ${ }^{14}$ The control group received two subcutaneous injections of the indomethacin vehicle, $5 \%$ $\mathrm{NaHCO}_{3}$, while group 1 received the indomethacin.

When arterial pressure and erythrocyte velocity were stabile during superfusion with BBS, images from the mesenteric preparations - about 10 venules per animal - were videotaped for five minutes. The number of venules (and rats) evaluated in the control group and in groups 1, 2, 3, and 4 were 52 (5), 69 (7), 61 (6), 58 (6), and 60 (6), respectively.

\section{Tissue analysis}

After intravital microscopy the animals were killed with an overdose of pentobarbital and the intestines were excised and opened longitudinally. Gross findings were ranked using the following criteria: 0 - no change in serosa or mucosa, 1 - hyperaemic lesions or petechial bleeding, or both, 2 - single mucosal erosion or ulceration, 3 - multiple erosions or ulcerations without any lesions in the serosa and mesentery, or single mucosal erosion or ulcer with hyperaemic, adhesive or haemorrhagic lesions in the serosa, 4-multiple erosions or ulcerations (less than $10 \mathrm{~cm}$ ) with hyperaemic, adhesive or haemorrhagic lesions in the serosa, 5 - multiple erosions or ulcerations (more than 


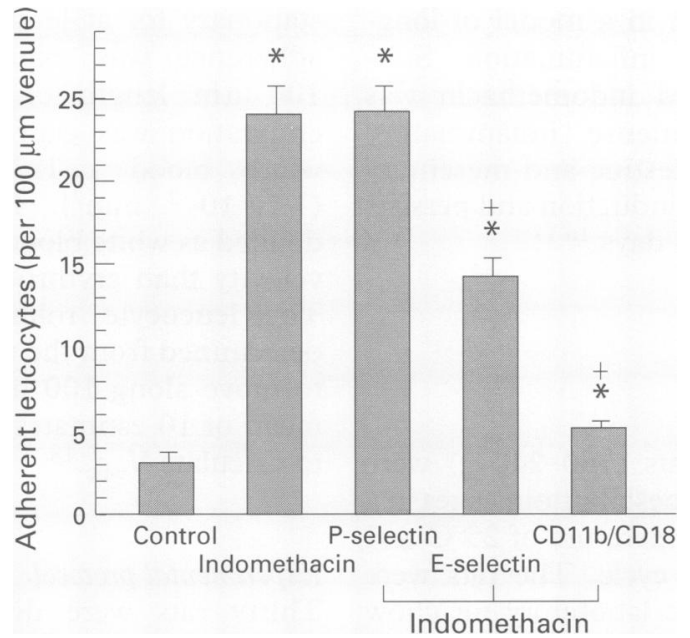

Figure 1: Effects of MAbs to P-selectin, E-selectin, and $C D 11 b / C D 18$ on indomethacin induced leucocyte adherence in rat mesenteric venules. Data shown as mean (SEM). ${ }^{\star} p<0.05$ compared with control, $\dagger p<0.05$ compared with indomethacin.

$10 \mathrm{~cm}$ ) with hyperaemic, adhesive or haemorrhagic lesions in the serosa. ${ }^{17}$

\section{Myeloperoxidase activity}

Intestinal tissue samples were rapidly excised, rinsed with ice cold saline, blotted dry, and frozen at $-70^{\circ} \mathrm{C}$ until thawing for determination of myeloperoxidase activity using methods previously described. ${ }^{24}$ Briefly, intestinal tissue was homogenised in $20 \mathrm{mM}$ phosphate buffer (pH 7.4) and centrifuged at $20000 \mathrm{~g}$ for 20 minutes at $4^{\circ} \mathrm{C}$. The pellet was homogenised and sonicated with an equivalent volume of 50 $\mathrm{mM} \mathrm{KP} \mathrm{K}_{\mathrm{i}}$ buffer containing $0.5 \%$ hexadecyltrimethylammonium bromide (HETAB). After centrifugation the supernatant was used for myeloperoxidase assay (measuring the $\mathrm{H}_{2} \mathrm{O}_{2}$ dependent oxidation of $3,3^{\prime} 5,5^{\prime}$ tetramethylbenzidine).

\section{Statistics}

All data were analysed using standard statistical analysis - that is, analysis of variance with

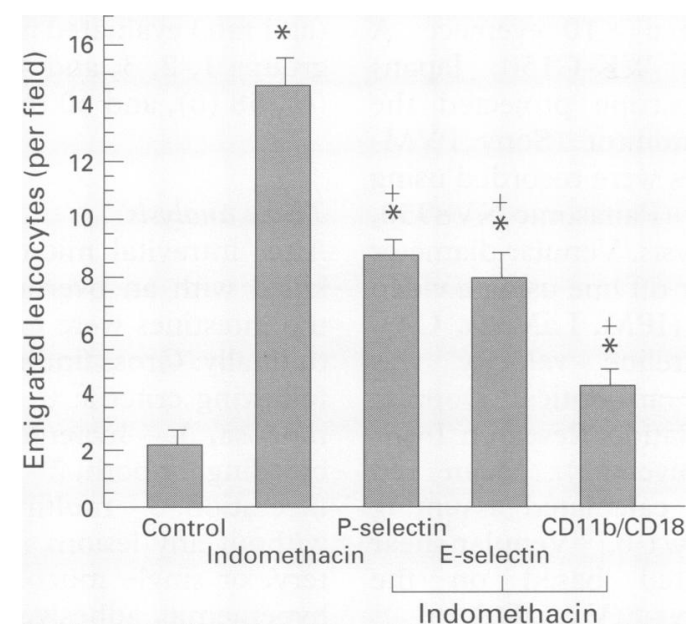

Figure 2: Effects of $M A$ bs to P-selectin, E-selectin, and $C D 11 \mathrm{~b} / \mathrm{CD} 18$ on indomethacin induced leucocyte emigration in rat mesenteric venules. Data shown as mean (SEM). ${ }^{\star} p<0.05$ compared with control, $t p<0.05$ compared with indomethacin.

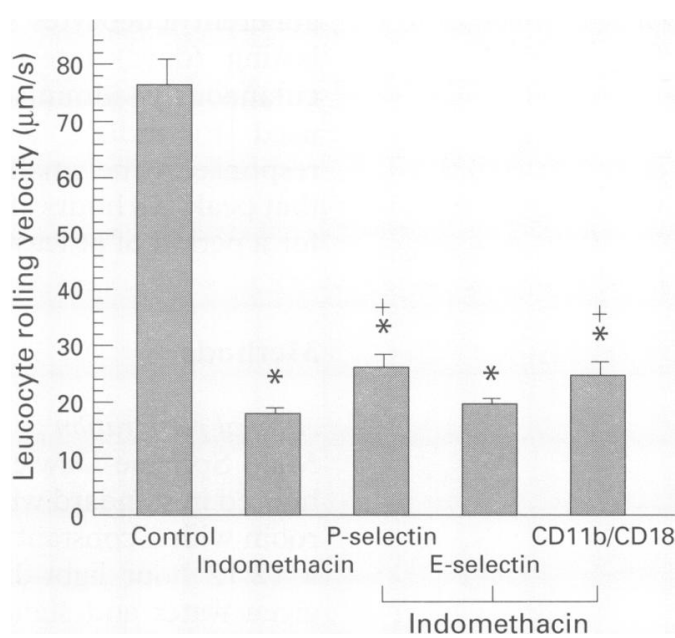

Figure 3: Effects of $M A$ bs to P-selectin, E-selectin, and $C D 11 \mathrm{~b} / C D 18$ on indomethacin effected leucocyte rolling velocity in rat mesenteric venules. Data shown as mean (SEM). ${ }^{\star} p<0.05$ compared with control, $+p<0.05$ compared with indomethacin.

the Scheffe's (posthoc) test. All values are expressed as means (SEM), statistical significance was set at $\mathrm{p}<0 \cdot 05$.

\section{Results}

Figure 1 summarises the effects of the various MAbs on the indomethacin induced increase in leucocyte adherence in rat mesenteric venules compared with untreated rats. Two subcutaneous injections of indomethacin elicited a nearly eightfold increase in adherence $(24.0(1.6) v 3.1(0.6)$ leucocytes per $100 \mu \mathrm{m}$ venule in control). While the anti-P-selectin antibody had no effect $(24 \cdot 2(1 \cdot 5))$, the anti-Eselectin $(14 \cdot 2(1 \cdot 1))$ and anti-CD11b $(5 \cdot 2$ $(0 \cdot 4))$ MAbs significantly reduced the number of adherent leucocytes.

The sixfold increase in leucocyte emigration (Fig 2) resulting from indomethacin injections $(14.5(1.0) v 2.2(0.6)$ leucocytes per field in control) was significantly blunted by anti-Pselectin $(8 \cdot 7(0 \cdot 6))$, anti-E-selectin $(7 \cdot 9(0.9))$, and anti-CD1 1b (4.2 (0.6)) MAbs.

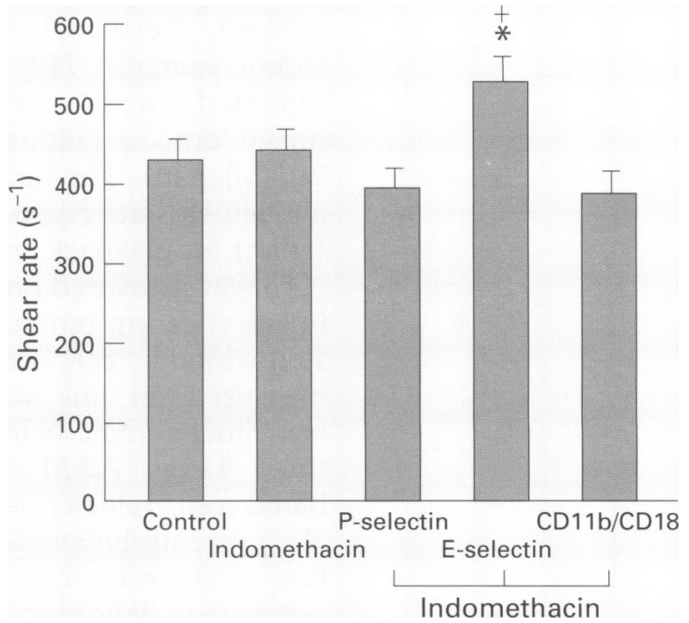

Figure 4: Effects of $M A$ bs to P-selectin, E-selectin, and $C D 11 b / C D 18$ on indomethacin effected venular wall shear rate in rat mesenteric venules. Data shown as mean (SEM). ${ }^{\star} p<0.05$ compared with control, $t_{p}<0.05$ compared with indomethacin. 
Effects of indomethacin and the MAbs to P-selectin, E-selectin, and CD11b/CD18 on mucosal ulceration and tissue myeloperoxidase activity

\begin{tabular}{|c|c|c|c|c|c|}
\hline & Control & Indomethacin & $\begin{array}{l}\text { P-selectin } \\
M A b\end{array}$ & $\begin{array}{l}\text { E-selectin } \\
M A b\end{array}$ & $\begin{array}{l}C D 11 b \\
M A b\end{array}$ \\
\hline $\begin{array}{l}\text { Mucosal ulceration } \\
\text { Myeloperoxidase (U/g ww) }\end{array}$ & $\begin{array}{l}0 \\
47 \cdot 2(4 \cdot 0)\end{array}$ & $\begin{array}{c}4 \cdot 0(0 \cdot 6)^{\star} \\
90 \cdot 1(12 \cdot 9)^{\star}\end{array}$ & $\begin{array}{l}3 \cdot 0(0 \cdot 7)^{\star} \\
53 \cdot 4(7 \cdot 1) \dagger\end{array}$ & $\begin{array}{r}2 \cdot 8(0 \cdot 4)^{\star} \\
48 \cdot 4(4 \cdot 8) \dagger\end{array}$ & $\begin{array}{r}3.9(0.4)^{\star} \\
42.9(10.9) \dagger\end{array}$ \\
\hline
\end{tabular}

The leucocyte rolling velocity (Fig 3) was reduced by $77 \%$ in response to indomethacin treatment $(17.6(1.2) v 76.2(5.0) \mu \mathrm{m} / \mathrm{s}$ in control). While the anti-E-selectin antibody had no effect on this response to indomethacin $(19.5(1 \cdot 1))$, the groups treated with either the anti-P-selectin $(26 \cdot 1(2 \cdot 1))$ or anti-CD $11 \mathrm{~b}$ $(24.5(2 \cdot 8))$ MAbs showed a small but significant increase in rolling velocity, compared with indomethacin treatment alone.

The venular wall shear rate (Fig 4) was not affected by any of the treatments (control 432 (27) $\mathrm{s}^{-1}$, indomethacin 441 (29), anti-Pselectin 394 (25), anti-CD11b 386 (29)) except the anti-E-selectin (525 (32)) antibody, which resulted in a slight increase compared with either control or indomethacin treated groups.

The indomethacin induced increase of leucocyte adhesion in mesenteric venules was accompanied by macroscopic mucosal ulcerations of the small bowel (ulcer index $4.0(0 \cdot 6)$ $v 0$ in control) and an increase of myeloperoxidase activity $(90 \cdot 1(13.0) \mathrm{U} / \mathrm{g}$ wet weight $v$ $47 \cdot 2(4 \cdot 0)$ in control), an index of granulocyte infiltration into the inflamed tissue. While the macroscopic extent of ulceration was not significantly reduced by antibody treatment all antibodies blunted the indomethacin induced increase in myeloperoxidase activity (Table).

\section{Discussion}

Leucocyte-endothelial cell adhesion is a complex process involving several families of adhesion molecules, including the leucocyte specific $\beta_{2}$-integrins (CD11/CD18), the endothelial cell associated immunoglobulins (ICAMs), and the selectins. The relative importance of these adhesion molecules to the process of leucocyte adhesion (leucocyte rolling, adhesion, and emigration) has been largely assessed using isolated neutrophils and monolayers of cultured endothelial cells. There have been only a few reports that assess the importance of adhesion molecules in modulating leucocyte adhesion within the microcirculation. ${ }^{13-1525}$

In vivo studies show that leucocyte rolling in postcapillary venules is mediated by $\mathrm{P}$-selectin on endothelial cells and L-selectin on the surface of leucocytes. ${ }^{2526}$ In the report by Zimmerman and coworkers ${ }^{14}$ the role of adhesion molecules in an acute (by superfusion of the venular preparation) leukotriene $\mathbf{B}_{4}$ and platelet activating factor induced increase in leucocyte-endothelial cell adhesion was examined in rat mesenteric venules. While MAbs against CD11b, CD18, ICAM-1, and E-selectin significantly reduced leucocyte adherence and emigration elicited by both lipid inflammatory mediators, the MAb against $P$-selectin reduced neutrophil rolling only under conditions of platelet activating factor induced inflammation.

In this study, we investigated the influence of CD11b, P- and E-selectin on leucocyteendothelial cell adhesion in postcapillary venules of animals with indomethacin induced intestinal inflammation. While acute exposure of mesenteric venules to indomethacin by superfusion increases leucocyte adherence through a leuketriene $B_{4}$ dependent mechanism $^{27}$ neither leuketriene $B_{4}$ nor platelet activating factor seem to contribute to the leucocyte-endothelial cell adhesion induced in our model of inflammation where indomethacin was given 48 and 24 hours before the experiment. ${ }^{16}$ Thus, it seems probable that the pattern of adhesion molecule involvement will differ between the inflammatory responses elicited by acute (minutes) $v$ chronic (days) treatment with indomethacin. Indeed, in a recent study by Wallace et al ${ }^{28}$ it was noted that acute exposure of the rat mesentery to indomethacin by superfusion elicited the recruitment of adherent leucocytes in postcapillary venules, a response that was attenuated by MAbs directed against either the $\beta$-subunit (CD18) of CD11/CD18, ICAM-1 or P-selectin, but not E-selectin. These findings contrast with our findings that show no involvement of $\mathrm{P}$-selectin but a significant role for E-selectin in mediating the leucocyte adherence responses in a model of indomethacin induced inflammation lasting for days. A common feature to both studies, however, is the absolute requirement for the CD11/CD18 adhesion glycoprotein in mediating leucocyte adherence.

The ineffectiveness of a P-selectin MAb in reducing leucocyte adherence in our model does not negate a role for this adhesion molecule in the overall inflammatory process elicited by chronic administration of indomethacin. This contention is supported by the significant reduction in indomethacin induced leucocyte emigration seen in animals pretreated with the P-selectin MAb. An explanation for the lack of effect on leucocyte adherence with a corresponding reduction in leucocyte emigration may lie in the kinetics of $P$-selectin expression on activated endothelial cells. Most stimuli for P-selectin mobilisation from its normal storage site in Weibel-Palade bodies have been shown to cause a transient increase in adhesion molecule expression, lasting minutes rather than hours. ${ }^{56}$ Consequently, at the time of observation of the mesenteric venules some two days after the initial indomethacin injection it is probable that P-selectin was no longer expressed to a significant extent on the endothelial cell surface and the adhesion molecule did not contribute to leucocyte adherence. As the $P$-selectin $\mathrm{MAb}$ may have greatly reduced leucocyte adhesion, however, in the early phase of the inflammatory response to indomethacin, then the total number of emigrated leucocytes was correspondingly 
reduced. This explanation is further supported by our finding that the P-selectin MAb significantly reduced the granulocyte accumulation in the intestinal mucosa that was normally seen in the indomethacin model. Tissue associated myeloperoxidase activity, a measure of granulocyte number in a tissue, should reflect the cumulative number of emigrated leucocytes. ${ }^{24}$

In the few published studies that examine the importance of E-selectin in mediating leucocyte adherence in postcapillary venules, the endothelial cell adhesion molecule has not been very effective in preventing or reducing leucocyte recruitment. ${ }^{1528}$ This lack of effect of E-selectin MAbs in reducing leucocyte adhesion in some experimental models may be related to the kinetics of expression of this adhesion molecule. In response to agents such as endotoxin or interleukin 1, increased surface expressions of the molecule are seen within one to two hours with maximal expression occurring at four to six hours. ${ }^{7}$ Unlike P-selectin, which is normally stored within endothelial cells, E-selectin expression requires de novo protein synthesis. ${ }^{25}$ The effectiveness of an E-selectin $\mathrm{MAb}$ in our study most probably reflects an induction of adhesion molecule synthesis and increased surface expression in response to indomethacin given longterm.

Measurements of myeloperoxidase activity in the intestine of indomethacin treated animals showed that the leucocyte adhesion and emigration seen in mesenteric venules were accompanied by a significant accumulation of granulocytes in the gut mucosa. Furthermore, the ability of the different MAbs to reduce leucocyte emigration in mesenteric venules was also accompanied by an attenuated accumulation of granulocytes in the intestinal mucosa. It is important to note, however, that while the MAbs were very effective in preventing the granulocyte accumulation, no protection was afforded against the intestinal mucosal ulcerations normally elicited by this regimen of indomethacin treatment. The lack of protection against intestinal ulceration despite a blunted myeloperoxidase activity in intestinal tissue (reduced granulocyte accumulation) was already recognised in the same model of inflammation in animals rendered neutropenic ${ }^{17}$ and in animals treated with metronidazole, which inhibits the indomethacin induced leucocyte-endothelial cell adhesion (Arndt et al, unpublished results). These findings show that granulocyte recruitment into the intestinal mucosa in this experimental model is a consequence, rather than a cause, of the mucosal lesions. The fact that MAbs diminish the gastric ulcer formation after indomethacin administration ${ }^{28}$ could result from different mechanisms of ulcer formation, which depend on feeding (intestinal ulcers) or starvation (gastric ulcers) after the indomethacin injection or the different time course of the experiments (three hours after indomethacin administration in Wallace et $a l^{28}$ $v 48$ hours in this study). Our finding that indomethacin induced ulcer formation is not influenced by circulating/emigrating granulocytes could be explained by either resident granulocytes, which are not influenced by the antibody induced reduction of granulocyte emigration or by macrophages - either resident or emigrating out of the vasculature. As the method of intravital microscopy used in both studies does not allow us to discriminate the different types of leucocytes that adhere and emigrate across the microvessels the physiological basis for the different responses in the two models of mucosal injury warrants further experimentation.

Supported by a grant from the National Institutes of Health (PO1-DK 43785).

1 McEver R. GMP 140: a receptor for neutrophils and monocytes on activated platelets and endothelium f Cell Biochem 1991 a; 45: 156-61.

2 Paulson JC. Selectin/carbohydrate-mediated adhesion of leukocytes. In: Harlan JM, Liu DY, eds. Adhesion: its role in inflammatory disease. New York: Freeman, 1992: 19-42.

3 Polley MJ, Phillips ML, Wayner E, Nudelman E, Singhal AK, Hakomori SI, et al CD62 and endothelial cell-leukoAK, cyte adhesion molecule 1 (ELAM-1) recognize the same Carbohydrate ligand, si $1991 ; 88$ : 6224-8.

4 Lawrence MB, Springer TA. Leukocytes roll on a selectin at physiologic flow rates: distinction from and prerequisite for adhesion through integrins. Cell 1991; 65: 859-73.

5 McEver R. Leukocyte interactions mediated by selectins. Thromb Haemostasis 1991b; 66: 80-7.

6 Patel KD, Zimmerman GA, Prescott SM, McEver RP McIntyre TM. Oxygen radicals induce human endothelia cells to express GMP-140 and bind neutrophils. $\mathcal{f}$ Cell Biol 1991; 112: 749-59.

7 Bevilacqua MP, Pober JS, Mendrick DL, Cotran RS, Gimbrone Jr MA. Identification of an inducible endothelial-leukocyte adhesion molecule. Proc Natl Acad Sci thelial-leukocyte adhesion

8 Berg EL, Robinson MK, Mansson O, Butcher EC Magnani JL. A carbohydrate domain common to both sialyl $L e$ a and sialyl $L e x$ is recognized by the endothelia leukocyte adhesion molecule ELAM-1. f Biol Chem 1991; leukocyte adhesion

9 Phillips ML, Nudelman E, Gaete FCA, Perez M, Singhal AK, Hakomori SI, et al. ELAM-1 mediates cell adhesion by recognition of a carbohydrate ligand, sialyl Le $\mathbf{x}$. Science 1990; 250: 1130-2.

10 Luscinskas FW, Cybulski MI, Kiely J-M, Peckins CS, Davis VM, Gimbrone Jr MA. Cytokine-activated human endothelial monolayers support enhanced neutrophil transmigration via a mechanism involving both endothelial-leukocyte adhesion molecule-1 and intercellular thelial-leukocyte adhesion molecule-1 and intercell

11 Smith CW, Rothlein R, Hughes BJ, Mariscalo MM, Rudloff $\mathrm{HE}$, Schmalstieg FC, et al. Recognition of an endothelial determinant for CD18-dependent human neutrophil adherence and transendothelial migration. $f$ Clin Inves 1988; 82: 1746-56.

12 Furie MB, Maria CA, Smith CW. Monoclonal antibodies to leukocyte integrins $\mathrm{CD} 11 \mathrm{a} / \mathrm{CD} 18$ and $\mathrm{CD} 11 \mathrm{~b} / \mathrm{CD} 18$ or intercellular adhesion molecule-1 inhibit chemoattractant-stimulated neutrophil transendothelial migration in vitro. Blood 1991; 78: 2089-97.

13 Bienvenu K, Granger DN. Molecular determinants of shear-rate dependent leukocyte adhesion in postcapillary venules. Am f Physiol 1993; 264: H1504-8.

14 Zimmerman BJ, Holt JW, Paulson JC, Anderson DC, Miyasaka M, Tamatani T, et al. Molecular determinants Miyasaka M, Tamatani T, et al. Molecular determinants
of lipid-mediator-induced leukocyte adherence and emiof lipid-mediator-induced leukocyte adherence and emi-
gration in rat mesenteric venules. Am $\mathcal{F}$ Physiol 1994; 266: gration in

15 Kurose I, Kubes P, Wolf R, Anderson DC, Paulson JC, Miyasaka $M$, et al. Inhibition of nitric oxide production. Mechanisms of vascular albumin leakage. Circ Res 1993 73: $164-71$.

16 Arndt H, Yamada T, Grisham MB, Granger DN. Systemic microcirculatory disturbances induced by indomethacin. Gastroenterology 1992; 102 (suppl): A34.

17 Yamada T, Deitch E, Specian RD, Perry MA, Sator RB, Grisham MB. Mechanisms of acute and chronic intestinal inflammation induced by indomethacin. Inflammation 1993; 17: 641-62.

18 Arndt H, Smith CW, Granger DN. Leukocyte-endothelial cell adhesion in spontaneously hypertensive and normocell adhesion in spontaneously hypertensive

19 Granger DN, Benoit JN, Suzuki M, Grisham MB. Leukocyte adherence to venular endothelium during ischemia/reperfusion. Am $\mathcal{f}$ Physiol 1989; 257: G683-8.

20 Davis MJ. Determination of volumetric flow in capillary tubes using an optical Doppler velocimeter. Microvasc Res 1987; 34: 223-30.

21 House SD, Lipowsky $H$. Leukocyte-endothelium adhesion microhemodynamics in mesentery of the cat. Microvasc Res 1987; 34: 363-79.

22 Mulligan MS, Wilson GP, Todd RF III, Rusche JR, Smith $\mathrm{CW}$, Anderson DC, et al. Role of $\mathrm{B}_{1}, \mathrm{~B}_{2}$ integrins and ICAM-1 in lung injury following deposition of IgG and IgA immune complexes. F Immunol 1993; 150: 2407-17. 
23 Mulligan MS, Polley MJ, Bayer RJ, Nunn MF, Paulson JC Ward PA. Neutrophil-dependent acute lung injury. Requirement for P-selectin (GMP-140). $f$ Clin Invest 1992; 90: 1600-7.

24 Grisham MB, Benoit JN, Granger DN. Assessment of leukocyte involvement during ischemia and reperfusion of intestine. Methods Enzymol 1990; 186: 729-42.

25 Bevilacqua MP, Stengelin S, Gimbrone Jr MA, Seed B. Endothelial leuke Endothelial leukocyte adhesion molec receptor for neutrophils related to complement regulatory
proteins and lectins. Science 1989; 243: 1160-5.
26 Doré M, Korthuis RJ, Granger DN, Entman ML, Smith CW. P-selectin mediates spontaneous leukocyte rolling in vivo. Blood 1993; 82: 1308-16.

27 Asako H, Kubes P, Wallace J, Gaginella T, Wolf RE, Granger DN. Indomethacin-induced leukocyte adhesion in mesenteric venules: role of lipoxygenase products. Am F Physiol 1992; 262: G903-8.

28 Wallace JL, McKnight W, Miyasaka M, Tamatani $T$ Paule J, McKnight W, Miyasaka $M$, Tamatani T, Paulson J, Anderson DC, et al. Role of endothelial
adhesion molecules in NSAID- induced gastric mucosal injury. Am $\mathcal{F}$ Physiol 1993; 265: G993-8. 